\section{Doi: $10.15863 / \mathrm{TAS}$ \\ International Scientific Journal Theoretical \& Applied Science}

p-ISSN: 2308-4944 (print)

e-ISSN: 2409-0085 (online)

Year: 2015 Issue: $01 \quad$ Volume: 21

Published: $30.01 .2015 \quad$ http://www.T-Science.org

SECTION 21. Pedagogy. Psychology. Innovations in the field of education.
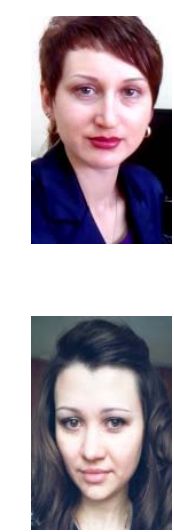

Yuliya Pavlovna Kuzmenko Master of Science in

Teaching and Psychology, Senior teacher of the preschool, primary and special education department,

Kostanay State Pedagogical Institute, Kazakhstan yulyazilowa@mail.ru

Anastassiya Sergeevna Ukolova Student of the specialty «Defectology» Kostanay State Pedagogical Institute, Kazakhstan luntic.93@,mail.ru

\title{
TO THE QUESTION OF NEEDS NONTRADITIONAL OF DRAWING TECHNIQUE FOR DEVELOPMENT OF CREATIVE IMAGINATION OF MENTALLY RETARDED YOUNGER SCHOOL STUDENTS
}

Abstract: Development of creative imagination in mentally retarded younger school students is realized through nontraditional of drawing techniques. We describe nontraditional of drawing techniques which, in our opinion, need to be used at drawing lessons at correctional school in this article. Nontraditional of drawing techniques open for mentally retarded younger school students opportunity to think unconventionally.

Key words: mentally retarded schoolchildren, nontraditional of drawing techniques, creative imagination.

Language: Russian

Citation: Kuzmenko YP, Ukolova AS (2015) TO THE QUESTION OF NEEDS NONTRADITIONAL OF DRAWING TECHNIQUE FOR DEVELOPMENT OF CREATIVE IMAGINATION OF MENTALLY RETARDED YOUNGER SCHOOL STUDENTS. ISJ Theoretical \& Applied Science 01 (21): 49-54. doi: http://dx.doi.org/10.15863/TAS.2015.01.21.8

\section{К ВОПРОСУ О НЕОБХОДИМОСТИ ИСПОЛЬЗОВАНИЯ НЕТРАДИЦИОННЫХ ТЕХНИК РИСОВАНИЯ ДЛЯ РАЗВИТИЯ ТВОРЧЕСКОГО ВООБРАЖЕНИЯ УМСТВЕННО ОТСТАЛЫХ МЛАДШИХ ШКОЛЬНИКОВ}

Аннотация: Развитие творческого воображения у умственно отстальх младиих икольников реализуется через нетрадиционные техники рисования. $B$ данной статье мы описываем нетрадиционные техники рисования, которые, на наш взгляд, необходимо использовать на уроках рисования в коррекциионой школе. Нетрадиционные техники рисования открывают умственно отсталым младшим школьникам возможность мыслить нестандартно.

Ключевые слова: умственно отсталье младиие школьники, нетрадиционные техники рисования, творческое воображение.

«Мир будет счастлив только тогда, когда у каждого человека будет душа художника.

Иначе говоря, когда каждый будет находить радость в своем труде»... Роден

\section{Введение}

Умственная отсталость - это стойко нарушенная познавательная деятельность вследствие органического поражения головного мозга (наследуемого или приобретенного), имеющего диффузный, т.е. широко распространенный, как бы разлитой характер.
Умственно отсталые младшие школьники неспособны действовать в воображаемой ситуации и с воображаемыми предметами. Действия «как будто», «понарошку», типичные для нормальных детей этого возраста, у них, как правило, отсутствуют. Необходимо уделять внимание обогащению опыта детей, знакомить их с назначением предметов, показывать разнообразие использования этих предметов в зависимости от ситуаций. Естественно, что это будет способствовать развитию воображения детей. 
О.П. Гаврилушкина отмечает, что у умственно отсталых детей из-за чрезвычайно ограниченного опыта предметных и игровых действий функциональная сторона реальных объектов долго остается непознанной. В результате затрудняются операции с предметами и их изображениями, требующие замещения и т.д. О.П. Гаврилушкина отводит важную роль при обучении рисованию, лепке, выполнению изображения с натуры. Эта работа связана с развитием восприятия и формированием представлений у детей. Это мостик к «свободному» рисованию, созданию собственного сюжета и композиций, что возможно лишь при наличии воображения.[1]

Что же такое творчество? Для ответа на этот вопрос мы обратились к словарям. Понятий творчества очень много. Так, например, в толковом словаре русского языка С.И. Ожегова u Н.Ю. Шведова, понятие «творчество» понимается как создание новых по замыслу культурных или материальных ценностей.[2] В русском толковом словаре великого русского языка Т.Ф. Ефремовой понятие «творческое воображение» рассматривается как: 1) Деятельность человека, направленная на создание духовных и материальных ценностей. 2) То, что создано в результате такой деятельности.[3]

Как много определений понятия «творчество», так же много и видов воображения: активное и пассивное, продуктивное и репродуктивное, произвольное и непроизвольное, воссоздающее и творческое.

Нас интересует именно творческое воображение. Понятий творческого воображения множество. Например, С.Ю. Головин, под творческим воображением понимает самостоятельное создание образа, вещи, признака, не имеющих аналогов, новых; реализуемых в оригинальных и ценных продуктах деятельности. Неотъемлемая сторона технического, художественного и иного творчества.[4] В Большой энциклопедии по психиатрии понятие «творческое воображение» трактуется как процесс творчества, создания новых идей, решений, теорий. Разумеется, их автор заранее не знает окончательного решения проблемы, ему известны только те общие критерии, которым оно должно отвечать. Исследователь, пытаясь формулировать гипотезу или теорию, должен, например, конструировать некую ментальную структуру, которая дает возможность непротиворечивым образом связать определенную группу фактических данных. Писатель, сочиняя роман, стремится из множества наблюдений выстроить такую последовательность изображаемых событий, которые отвечают его философской или гражданской позиции, которые прямо он чаще всего не формулирует, да и едва ли сумеет это сделать, если он к тому же не ученый или философ.[5] Творческое воображение, по определению, Конюхова Н.И., это вид воображения, базирующийся на самостоятельном создании образов объектов, не существующих в настоящее время, или воспроизведении оригинальной модификации уже имеющегося объекта, явления; это нестандартный образ нечто ранее описанного, прочитанного, воспринятого.[6] Урунтаева Г.А. даёт понятию «творческое воображение» следующее определение: вид воображения, предполагающий создание оригинального продукта.[7]

Мы дали авторское понятие «творческому воображению умственно отсталого младшего школьника» относительно нашего исследования. Итак, творческое воображение умственно отсталого младшего школьника понимается нами как особый вид воображения, процесс самостоятельного создания оригинального продукта деятельности с помощью нетрадиционных техник рисования (на уроках изобразительной деятельности).

Мы полагаем, что через нетрадиционные техники рисования можно развить интерес к изобразительному искусству, творческие способности, а главное активизировать творческое воображение умственно отсталых младших школьников. Нетрадиционные техники рисования - это толчок к развитию творческого воображения, проявлению самостоятельности, инициативы, выражения индивидуальности, это «отрыв от стереотипности».

Изобразительная деятельность имеет значение для всестороннего нравственного, трудового и умственного развития детей. Творчество является одним из возможностей передачи ребенком своих впечатлений об окружающем мире, передать образы воображения, воплотить их с помощью разнообразных материалов. Рисование необычными материалами и оригинальными техниками позволяет детям использовать знакомые предметы в качестве художественного материала, вызвать интерес к изобразительному искусству.

Изобразительная деятельность создаёт благоприятные условия для изучения специфических особенностей умственно отсталых младших школьников в плане ориентировки в пространстве и умения располагать объекты на плоскости листа бумаги. Кроме того, проверяется, как школьник, 
анализируя объект изображения, называет его части и словесно обозначает взаимное расположение этих частей.

Нетрадиционные техники рисования позволяет не ограничивать проявления творческих способностей детей, не ставя их в рамки «образцы и показа» приемов рисования и их последовательности; не навязывая детям свою точку зрения на окружающий мир, даёт им возможность реализовать свой творческий потенциал.[8]

Оригинальное рисование раскрывает креативные возможности ребенка; позволяет почувствовать краски, их характер, настроение.

Рисуя необычным материалом, школьник может раскрыть самые неожиданные, непредсказуемые варианты художественного изображения и стать толчком развития творческого воображения и фантазирования.

Рисовать можно чем угодно, это позволяет ребенку научиться выражать свои чувства, учиться преодолевать робость, стеснение, развивать уверенность в себе и своих действиях, преодолевать страх, перед тем, правильно он выполнил работу или нет.

Учеными изучено и освоено более 30 различных техник рисования: техника тычка, рисование пальчиками, рисование ладошкой, оттиск пробкой, печатками, ластиком, оттиск поролоном, пенопластом, оттиск смятой бумагой, обрывание бумаги, скатывание бумаги, рисование восковыми мелками и акварелью, рисование свечей и акварелью, монотипия приоритетов, монотипия пейзажная, кляксография, набрызг, тиснение, тычкование, цветной граттаж, черно-белый граттаж, рисование акварельными мелками, рисование нитками, рисование солью, рисование пластилином, рисование опилками.

Опытно-экспериментальная работа. Для развития творческого воображения умственно отсталых младших школьников мы предлагаем использовать следующие нетрадиционные техники рисования:

1. Рисование свечой - очень интересная техника рисования, но очень трудоемкая, т.к. требует особого внимания. Когда ребенок рисует свечой то нарисованное плохо видно, и поэтому нужно тщательно продумывать сюжет и формы предметов, чтобы не было лишних штрихов. Затем делают фон и раскрашивают красками.

2. Монотипия бывает двух типов: монотипия при сгибе листа - складывают лист пополам, на одной стороне рисуют половину предмета, а затем аккуратно сгибают лист и получается отпечаток (яблоки, бабочки); более сложная монотипия на одном листе: наносятся густые краски, затем к рисунку прикладывается другой лист и приглаживается, осторожно снимается (можно в сторону).

3. Рисование от пятна. Разлить тушь на листе, затем дуть в трубочку или веткой дерева, рисуя кусты, деревья, ветки и т.д.

4. Рисование губкой - смочить часть губки и обмакнуть ее в краску, чуть отжать и осторожно легко прикладывать к бумаге (трава, кусты, листья деревьев). Тонкую губку свернуть и закрепить скотчем, окрасить краской и печатать улиток или орнаменты.

5. Тычок жесткой полусухой кистью. Средства выразительности: фактурность окраски, цвет. Материалы: жесткая кисть, гуашь, бумага любого цвета и формата либо вырезанный силуэт пушистого или колючего животного. Способ получения изображения: ребенок опускает в гуашь кисть и ударяет ею по бумаге, держа вертикально. При работе кисть в воду не опускается. Таким образом, заполняется весь лист, контур или шаблон. Получается имитация фактурности пушистой или колючей поверхности.

6. Рисование пальчиками. Средства выразительности: пятно, точка, короткая линия, цвет. Материалы: мисочки с гуашью, плотная бумага любого цвета, небольшие листы, салфетки. Способ получения изображения: ребенок опускает в гуашь пальчик и наносит точки, пятнышки на бумагу. На каждый пальчик набирается краска разного цвета. После работы пальчики вытираются салфеткой, затем гуашь легко смывается.

7. Рисование ладошкой. Средства выразительности: пятно, цвет, фантастический силуэт. Материалы: широкие блюдечки с гуашью, кисть, плотная бумага любого цвета, листы большого формата, салфетки. Способ получения изображения: ребенок опускает в гуашь ладошку (всю кисть) или окрашивает ее с помощью кисточки (с 5-ти лет) и делает отпечаток на бумаге. Рисуют и правой и левой руками, окрашенными разными цветами. После работы руки вытираются салфеткой, затем гуашь легко смывается.[9]

Данные нетрадиционные техники дают толчок к развитию творческого воображения, проявлению самостоятельности, инициативности, индивидуальности.

Изобразительная деятельность с применением нетрадиционных техник рисования также способствует развитию у ребёнка:[10]

- Мелкой моторики рук и тактильного восприятия; 
- Пространственной ориентировки на листе бумаги, глазомера и зрительного восприятия;

- Внимания и усидчивости;

- Изобразительных навыков и умений, наблюдательности, эстетического восприятия, эмоциональной отзывчивости;

- Кроме того, в процессе этой деятельности у умственно отсталого младшего школьника формируются навыки контроля и самоконтроля.

Для диагностики творческого воображения мы используем методики «Солнце в комнате», «Как спасти зайку», «Складная картинка», «Дощечка» (авторы В. Кудрявцев и В. Синельников), «Дорисовывание фигур» (О.M. Дьяченко).

Опытно-экспериментальная работа проводиться на базе Костанайской коррекционной школы. Для развития творческого воображения умственно отсталых младших школьников нами разработана система уроков по изобразительной деятельности, включающая три этапа:

- $\quad$ пропедевтический - подготовка детей к работе с нетрадиционными техниками рисования;

- основной - проведение занятий по развитию творческого воображения;

- заключительный - закрепление полученных навыков в коллективных творческих работах.

Уроки проводятся согласно календарнотематическому плану Костанайской коррекционной школы.

Для примера представляем вырезку из календарно-тематического плана (3 четверть), разработанного нами с учетом использования нетрадиционных техник рисования в таблице 1 .

Таблица 1

Календарно-тематическое планирование по изобразительной деятельности (3 четверть) Костанайской коррекционной школы

\begin{tabular}{|c|c|c|c|c|c|c|c|}
\hline $\begin{array}{l}\text { № } \\
\Pi / \Pi\end{array}$ & Тема урока & Выполнение & $\begin{array}{l}\text { Техника } \\
\text { рисования }\end{array}$ & $\begin{array}{l}\text { Коррекционн } \\
\text { ая работа }\end{array}$ & Словарь & $\begin{array}{l}\text { Кол. } \\
\text { часов }\end{array}$ & дата \\
\hline \multicolumn{8}{|c|}{3 четверть } \\
\hline 1 & $\begin{array}{l}\text { Снеговики } \\
\text { (сюжетный } \\
\text { рисунок). }\end{array}$ & $\begin{array}{l}\text { Самостоятельн } \\
\text { ое выполнение } \\
\text { работы после } \\
\text { объяснения }\end{array}$ & $\begin{array}{l}\text { Тычок } \\
\text { жесткой } \\
\text { полусухой } \\
\text { кистью. }\end{array}$ & $\begin{array}{l}\text { Геометрическ } \\
\text { ий диктант. }\end{array}$ & $\begin{array}{l}\text { Снег, } \\
\text { снеговик, } \\
\text { круг. }\end{array}$ & 1 & 15.01 \\
\hline 2 & $\begin{array}{l}\text { Узор в } \\
\text { квадрате } \\
\text { (геометрическ } \\
\text { ий). }\end{array}$ & $\begin{array}{l}\text { Самостоятельн } \\
\text { ое выполнение } \\
\text { работы после } \\
\text { объяснения }\end{array}$ & $\begin{array}{l}\text { Печать по } \\
\text { трафарету }\end{array}$ & $\begin{array}{l}\text { К своим } \\
\text { игрушкам }\end{array}$ & $\begin{array}{l}\text { Квадрат, } \\
\text { круг, } \\
\text { треугольник. }\end{array}$ & 1 & 22.01 \\
\hline 3 & $\begin{array}{l}\text { Узор } \\
\text { квадрате } \\
\text { (растительный } \\
\text { ). }\end{array}$ & $\begin{array}{l}\text { Самостоятельн } \\
\text { ое выполнение } \\
\text { работы после } \\
\text { объяснения }\end{array}$ & $\begin{array}{l}\text { Кляксограф } \\
\text { ия } \quad \text { с } \\
\text { трубочки }\end{array}$ & $\begin{array}{ll}\text { На } & \text { что } \\
\text { похоже? } & \end{array}$ & $\begin{array}{l}\text { Квадрат, } \\
\text { ветка, лист. }\end{array}$ & 1 & 29.01 \\
\hline 4 & $\begin{array}{l}\text { Узор в } \\
\text { квадрате } \\
\text { (животный). }\end{array}$ & $\begin{array}{l}\text { Самостоятельн } \\
\text { ое выполнение } \\
\text { работы после } \\
\text { объяснения }\end{array}$ & $\begin{array}{l}\text { Печать по } \\
\text { трафарету }\end{array}$ & $\begin{array}{l}\text { Угадай } \quad \text { по } \\
\text { силуэту }\end{array}$ & $\begin{array}{l}\text { Квадрат, } \\
\text { трафарет, } \\
\text { животное. }\end{array}$ & 1 & 05.02 \\
\hline 5 & $\begin{array}{l}\text { Узор в круге } \\
\text { (декоративное } \\
\text { рисование). }\end{array}$ & $\begin{array}{l}\text { Самостоятельн } \\
\text { ое выполнение } \\
\text { работы после } \\
\text { объяснения }\end{array}$ & $\begin{array}{l}\text { Оттиск } \\
\text { пробкой }\end{array}$ & $\begin{array}{l}\text { Найди свою } \\
\text { игрушку }\end{array}$ & $\begin{array}{l}\text { Круг, } \\
\text { листья, } \\
\text { цветы. }\end{array}$ & 1 & 12.02 \\
\hline 6 & Пейзаж. & $\begin{array}{l}\text { Самостоятельн } \\
\text { ое выполнение } \\
\text { работы после } \\
\text { объяснения }\end{array}$ & $\begin{array}{l}\text { Монотипия } \\
\text { пейзажная }\end{array}$ & Прогулка & $\begin{array}{l}\text { Пейзаж, } \\
\text { горы, } \\
\text { деревья, } \\
\text { река. }\end{array}$ & 1 & 19.02 \\
\hline 7 & $\begin{array}{ll}\text { Рыбка } & \text { в } \\
\text { аквариуме. }\end{array}$ & $\begin{array}{l}\text { Самостоятельн } \\
\text { ое выполнение } \\
\text { работы после } \\
\text { объяснения }\end{array}$ & $\begin{array}{l}\text { Оттиск } \\
\text { смятой } \\
\text { бумагой }\end{array}$ & Рыбалка & $\begin{array}{l}\text { Рыбка, } \\
\text { название } \\
\text { частей тела, } \\
\text { аквариум. } \\
\end{array}$ & 1 & 26.02 \\
\hline 8 & Башенка & Самостоятельн & Монотипия & Собери & Башня, & 1 & 05.03 \\
\hline
\end{tabular}




\begin{tabular}{|c|c|c|c|c|c|c|c|}
\hline & $\begin{array}{l}\text { элементов } \\
\text { строительного } \\
\text { материала } \\
\text { (рис-е } \\
\text { натуры). }\end{array}$ & $\begin{array}{l}\text { ое выполнение } \\
\text { работы после } \\
\text { объяснения }\end{array}$ & предметная & башенку & $\begin{array}{l}\text { кубики, } \\
\text { выкладыван } \\
\text { ие. }\end{array}$ & & \\
\hline 9 & $\begin{array}{l}\text { «Цветок» } \\
\text { (элемент каз- } \\
\text { го орнамента). }\end{array}$ & $\begin{array}{l}\text { Самостоятельн } \\
\text { ое выполнение } \\
\text { работы после } \\
\text { объяснения }\end{array}$ & Тиснение & $\begin{array}{l}\text { Найди } \\
\text { бабочке свой } \\
\text { цветок }\end{array}$ & $\begin{array}{l}\text { Орнамент, } \\
\text { цветок. }\end{array}$ & 1 & 12.03 \\
\hline 10 & $\begin{array}{l}\text { Наурыз } \\
\text { (тематический } \\
\text { рисунок). }\end{array}$ & $\begin{array}{l}\text { Самостоятельн } \\
\text { ое выполнение } \\
\text { работы после } \\
\text { объяснения }\end{array}$ & $\begin{array}{l}\text { Кляксограф } \\
\text { ия } \quad \text { с } \\
\text { ниточкой }\end{array}$ & $\begin{array}{l}\text { Четвертый } \\
\text { лишний }\end{array}$ & $\begin{array}{l}\text { Наурыз, } \\
\text { праздник }\end{array}$ & 1 & 19.03 \\
\hline
\end{tabular}

Приведем пример урока по изобразительной деятельности с применением нетрадиционной техники рисования.

Тема: «Пейзаж»

Цель: развитие творческого воображения, художественного мышления и мелкой моторики.

Оборудование: листы A4, различные текстурные поверхности (выпуклые обои, салфетки с узором, пластинки от мозаики, пластиковые папки, копейки), цветные карандаши.

Увидев перед началом урока большое количество различных материалов, которые мы будем использовать на уроке, дети были заинтригованы, строили свои догадки по поводу темы предстоящего урока. И получив, наконец, инструкцию по выполнению задания с интересом принялись за работу.

Инструкция:

1. На листе бумаги изобразите пейзаж (река, горы, деревья, небо, солнце и т.п.);

2. Раскрасьте свой рисунок, прикладывая разные участки листа к разным поверхностям.

В начале урока детям были продемонстрированы картины казахстанского художника Сиденко Сергея Александровича с изображениями пейзажей. Для развития образного воображения работа проводилась под музыкальное сопровождение (Антонио Вивальди «Времена года»).

Заключение.

Подводя итог, хочется отметить, что уроки изобразительной деятельности с применением нетрадиционных техник рисования стали проходить интереснее и эмоциональнее, дети с удовольствием работают с материалом, который предлагается им для рисования, они вопросительно восклицают: «А что обоями (ниткой, пробкой) тоже можно рисовать?». И их удивлению нет предела, когда они видят свои «произведения».

К нетрадиционным техникам рисования можно отнести любой подручный материал. В перспективе, мы планируем создание новой нетрадиционной техники рисования.

В заключении, хотелось бы сказать, что использование нетрадиционных техник рисования на уроках изобразительной деятельности создают атмосферу самостоятельности, познавательной активности и инициативности, что положительно сказывается, на развитии мыслительной деятельности, эмоционально-волевой сферы, мелкой моторики, усидчивости, аккуратности, а главное творческого воображения умственно отсталых младших школьников.

\section{References:}

1. Borovik OV (1999) Formirovanie voobrajeniya umstvenno otstalikh uchaschikhsya mladshikh klassov. Dissertatsia kandidata pedagogicheskikh nauk.- Moscow: 1999.

2. (2015) Tolkovyy slovar' russkogo yazyka. S.I.Ozhegov, N.Yu.Shvedova. Available: http://ozhegov.info/slovar/?q=\%D0\%A2*\&pg $=11$ \&ind $=\mathrm{N} \quad$ (Accessed: 08.01.2015)
3. (2015) Tvorchestvo - etimologicheskaya spravka v elektronnom slovare Efremovoy Available:

http://slovonline.ru/slovar_efremova/b-19/id107001/tvorchestvo.html

(Accessed: 08.01.2015)

4. Golovin SY (1998) Slovar' prakticheskogo psikhologa, Minsk: Kharvest. 
5. Jmurov VA (2012) Bolshaya entsiklopedia po psokhiatrii, 2-e izd. Available: http://vocabulary.ru/dictionary/978 (Accessed: 08.01.2015)

6. Konykhov NI (1992) Prikladnie aspekti sovremennoy psikhologii: termini, zakoni, kontseptsii, metodi, 1992. Available: http://vocabulary.ru/dictionary/850 (Accessed: 08.01.2015)

7. Uruntaeva GA (2001) Doshkolnaya psikhologiya. 5-e izd. (Akademiya. 2001, 336s) Available: http://vocabulary.ru/dictionary/1019292 (Accessed: 08.01.2015)
8. (2008) Zanyatiya po risovaniyu $\mathrm{s}$ doshkolnikami/ Pod red. R.G. Kazakovoy Moscow: Tts Sfera.

9. (2015) Netraditsionnaya tekhnika risovaniya. Available:

http://student.zoomru.ru/isk/netradicionnayatehnika risovaniya/252237.2074776.s1.html (Accessed: 08.01.2015)

10. (2015) Ispol'zovanie netraditsionnykh sposobov risovaniya v doshkol'nom obrazovatel'nom uchrezhdenii Available: http://dou43.rybadm.ru/DswMedia/netradicion noerisovanie.docx (Accessed: 08.01.2015) 